\title{
Resistance to discrimination and subsequent resistance to extinction as a function of the sequence of partial S+ reward in differential conditioning
}

\author{
STEVEN J. HAGGBLOOM \\ Arkansas State University, State University, Arkansas 72467
}

\begin{abstract}
The effects of transitions from nonrewarded (N) to rewarded (R) trials (N-R transitions) on discriminative behavior in differential conditioning and subsequent resistance to extinction were investigated in two experiments. In Experiment 1, groups given N-R transitions within $\mathrm{S}+$ were more resistant to discrimination (ran fast in $\mathrm{S}-$ ) and extinction than were groups given a partial reinforcement (PRF) schedule in S+ devoid of N-R transitions. Experiment 2 indicated that $\mathrm{N}-\mathrm{R}$ transitions that occur when an $\mathrm{N}$ trial in $\mathrm{S}-$ is followed by an $\mathrm{R}$ trial in $\mathrm{S}+$ are as effective in increasing resistance to discrimination, but not resistance to extinction, as are $\mathrm{N}-\mathrm{R}$ transitions that occur within S+. The sequential effects obtained here were highly similar to those in conventional PRF and support the view that differential conditioning and PRF are highly interrelated phenomena. The results are discussed in terms of the extension of sequential theory to differential conditioning and the importance of internal reward-produced cues in discrimination learning.
\end{abstract}

Recent experiments in brightness differential conditioning (Capaldi, Berg, \& Morris, 1975; Haggbloom, 1978; McHose \& Blackwell, 1975) and in partial reinforcement (Capaldi, 1979) have emphasized the high degree of interrelatedness, both behavioral and theoretical, between partial reinforcement (PRF) and conventional discrimination learning. Many similarities between these situations have been described elsewhere (e.g., Capaldi, 1979; McHose \& Blackwell, 1975) and need not concern us here. Of interest in the present paper are similar effects of sequential variables on resistance to extinction following $P R F$ and behavior in the negative ( $\mathrm{S}-$ ) stimulus during discrimination learning, behavior that will be identified here as resistance to discrimination.

Among the more powerful sequential variables in both differential conditioning and PRF is that of transitions from nonrewarded $(\mathrm{N})$ to rewarded $(\mathrm{R})$ trials (N-R transitions). In differential conditioning, groups given trials to the positive $(\mathrm{S}+)$ stimulus following $\mathrm{S}-$ trials (transitions from an $\mathrm{N}$ trial in $\mathrm{S}-$ to an $\mathrm{R}$ trial in $\mathrm{S}+$, which we will call $\mathrm{S}-\mathrm{S}+$ transitions) develop appropriate discriminative behavior later in training than do groups that receive no $\mathrm{S}-\mathrm{S}+$

These experiments were supported in part by a grant from Arkansas State University and by National Institute of Mental Health Grant 1 ROC MH33349-01 to the author. The author wishes to thank Professor John K. Beadles for the use of laboratory space in the Department of Biology. Requests for reprints should be addressed to Steven J. Haggbloom, Department of Psychology, Arkansas State University, P.O. Box 2127, State University, Arkansas 72467. transitions within a day's trials (Capaldi et al., 1975; Haggbloom, 1978). S-S+ transitions also retard discrimination learning when small reward rather than nonreward is used in S- (Campbell \& Meyer, 1971; Meyer \& Campbell, 1973).

Haggbloom (1978) suggested that resistance to discrimination in groups given $\mathrm{S}-\mathrm{S}+$ transitions was due to the associative control over behavior acquired by the memory of nonreward $\left(\mathrm{S}^{\mathrm{N}}\right)$. According to the sequential view (Capaldi et al., 1975; Haggbloom, 1978), at least in the early trials of differential conditioning, $\mathrm{S}^{\mathrm{N}}$ occasioned by nonreward in $\mathrm{S}-$ is retrieved on the immediately subsequent trial whether that trial occurs in $\mathrm{S}-$ or $\mathrm{S}+\mathrm{S}-\mathrm{S}+$ transitions consequently function to condition responding to $\mathrm{S}^{\mathrm{N}}$. On subsequent occasions on which $\mathrm{S}^{\mathrm{N}}$ is recalled in $\mathrm{S}-$, the compound associative strength of $S^{N}$ and the $S-$ cue results in faster speeds than would be elicited by the $\mathrm{S}-$ cue alone. Resistance to discrimination is thus highly similar to resistance to extinction following PRF, which, according to the sequential view (e.g., Capaldi, 1966), is also regulated by the behavioral control acquired by $S^{N}$, in this case on $N-R$ transitions that occur within a single alley.

\section{EXPERIMENT 1}

$\mathrm{N}-\mathrm{R}$ transitions in differential conditioning may occur from $\mathrm{S}-$ to $\mathrm{S}+$ or within the $\mathrm{S}+$ alley if partial reward is employed in $\mathrm{S}+$. McHose and Blackwell (1975) reported two experiments that investigated the effects of N-R transitions contained in PRF schedules 
administered in $\mathrm{S}+$. All $\mathrm{S}$ - trials in both experiments were nonrewarded. In Experiment 1 , resistance to discrimination was greater in Group $N-R$, given $N-R$ transitions in $\mathrm{S}+$, than in Group $\mathrm{R}-\mathrm{N}$, given no $\mathrm{N}-\mathrm{R}$ transitions in $S+$. In Experiment 2, groups received one of three reward schedules in S+: RRN, RNR, or NRR. Although the RRN sequence did not provide $\mathrm{N}-\mathrm{R}$ transitions within $\mathrm{S}+$, resistance to discrimination was greater in Group RRN than in Groups RNR and NRR, which did not differ from each other.

The finding of greater resistance to discrimination in Group RRN than in Groups RNR and NRR would appear to be inconsistent with predictions derived from an application of sequential theory to differential conditioning (e.g., Capaldi et al., 1975; Haggbloom, 1978) and with the effects of S-S+ transitions described above. However, groups given different schedules of reward in $\mathrm{S}+$ in the McHose and Blackwell (1975) experiments were different in other ways as well. For example, all groups in both experiments, including Groups $\mathrm{R}-\mathrm{N}$ and $\mathrm{RRN}$, received $\mathrm{S}-\mathrm{S}+$ transitions. In both experiments, the total number of $\mathrm{N}-\mathrm{R}$ transitions experienced, for example, combining N-R transitions within $\mathrm{S}+$ with $\mathrm{S}-\mathrm{S}+$ transitions, was different among groups, as was the total number of transitions from $\mathrm{R}$ to $\mathrm{R}$ trials, $\mathrm{R}$ to $\mathrm{N}$ trials, and $\mathrm{N}$ to $\mathrm{N}$ trials. Indeed, in both experiments the number of consecutive $\mathbf{N}$ trials followed by an $\mathrm{R}$ trial ( $\mathrm{N}$-length), an important sequential variable governing resistance to extinction (Capaldi, 1966), was also different among groups.

McHose and Blackwell offered an interpretation of their results that was compatible with sequential theory, but that explanation involved several assumptions about the reinstatement of reward-related memories that await experimental verification. The central assumption was that the memory $\mathrm{S}^{\mathrm{N}}$ occasioned in $\mathrm{S}-$ is not retrieved until a subsequent $\mathrm{S}-$ trial even though there may be intervening $S+$ trials. Similarly, $S^{N}$ occasioned in $S+$ would be retrieved only on the next $S+$ trial. Capaldi et al. (1975) and Haggbloom (1978), on the other hand, have assumed that, at least in the early trials of differential conditioning, $\mathrm{S}^{\mathrm{N}}$ occasioned in $\mathrm{S}-$ is retrieved on the immediately subsequent trial whether that trial occurs in $\mathrm{S}+$ or $\mathrm{S}-$.

The purpose of Experiment 1 was to separate the effects on resistance to discrimination of (a) variations in reward sequence in $\mathrm{S}+$, using schedules similar to those used by McHose and Blackwell (1975, Experiment 2), from (b) variations in other sequential variables. This was accomplished by providing trials to the $\mathrm{S}+$ and $\mathrm{S}$ - discriminanda on alternate days. Under these conditions, it does not matter which of the two memory retrieval views is more nearly correct. In either case, groups given N-R transitions in $\mathrm{S}+$ would be expected to show greater resistance to discrimination than groups given no $\mathrm{N}-\mathrm{R}$ transitions in $\mathrm{S}+$.

Following discrimination training, groups received extinction in the $\mathrm{S}+$ alley. Since extinction is regulated by $\mathrm{S}^{\mathrm{N}}$, the extinction series provides additional information about the behavioral control acquired by $\mathrm{S}^{\mathrm{N}}$ during discrimination training.

\section{Method}

Subjects. The subjects were 36 male and 4 female rats, $90-110$ days old at the beginning of the experiment, bred in the laboratory from Holtzman stock.

Apparatus. The apparatus consisted of two parallel straight alleys, $105 \mathrm{~cm}$ long $\times 9 \mathrm{~cm}$ high and wide. The walls and floor of one alley were painted white, and the walls and floor of the other alley were painted black. The last $25 \mathrm{~cm}$ of each alley constituted a goalbox separated from the rest of the alley by a manually operated guillotine door. The doors and goalboxes were painted the same color as the alley in which they were located. Each goalbox contained an unpainted wooden goal cup. A gray startbox, $9 \mathrm{~cm}$ high and wide $\times 25 \mathrm{~cm}$ long, could be aligned to permit entry into one alley or the other. The startbox had a gray, manually operated guillotine door. Start times were recorded from the opening of the startbox door, which triggered a $1 / 100-\mathrm{sec}$ clock, to a point $32 \mathrm{~cm}$ into the alley. Run and goal times were recorded over the next 40 and $30 \mathrm{~cm}$, respectively, of the alley. The offset of the first clock and the operation of the run and goal clocks were controlled by photoelectric circuitry.

Procedure. Two weeks prior to the 1st day of experimental training, which began on Day 15, all food was removed from each rat's cage and a daily ration of $12 \mathrm{~g}$ of Purina Lab Chow was begun. The rats had free access to water at all times. On Days 12-14, the rats were handled in squads of four for $4 \mathrm{~min}$ per squad. After being handled on those days, the rats were fed eight 45-mg Noyes pellets in their home cage. Nine male rats and one female rat were assigned randomly to each of four groups.

Each group received four trials in the S+ alley on each oddnumbered day of training and three trials in the $S-$ alley on evennumbered days. A different number of trials was given on $\mathrm{S}+$ and $\mathrm{S}$ - days because pilot data had indicated that discrimination learning might occur so rapidly with four daily $S$ - trials that differences due to $\mathrm{S}+$ reward sequence would be obscured. Four trials on $\mathrm{S}+$ days seemed desirable because it allowed for a sched ule containing R-to-R-trial transitions for each group.

For one-half of the rats in each group, $\mathrm{S}+$ was the black alley and $\mathrm{S}-$ was the white alley. Those conditions were reversed for the other half of each group. Three experimental groups differed with respect to the schedule of $R$ and $N$ trials received on $S+$ days. The reward sequences employed were NRRR, RRNR, and RRRN The PRF groups will be identified by their respective reward schedule. Each experimental group received three consecutive $N$ trials on $S$ - days. A control group, Group CRF, received four rewarded ( $R$ ) trials on $S+$ days and three $R$ trials on $S-$ days. On $R$ trials, the rats were removed from the goalbox after the times were recorded (after approximately $10 \mathrm{sec}$ ) unless the reward had not yet been consumed. All reinforcements consisted of eight $45-\mathrm{mg}$ Noyes pellets. On $\mathrm{N}$ trials, the rats were confined to the unbaited goalbox for $20 \mathrm{sec}$.

There were 24 days of discrimination training, $12 \mathrm{~S}+$ days alternated with $12 \mathrm{~S}$ - days, followed by 3 days of extinction. During extinction, each group received five trials per day in the $S+$ alley. During both acquisition and extinction, a trial was begun by placing a rat in the startbox and opening the startbox door after approximately $3 \mathrm{sec}$ regardless of the rat's orientation. The rats were run in squads of four containing one rat from each group. The order in which trials were administered within a squad varied randomly from day to day, while the order of successive squads 
was held constant across days. The intertrial interval was 3-4 min. A maximum time of $30 \mathrm{sec}$ was allowed in each alley section. If $30 \mathrm{sec}$ was exceeded in any alley section, the additional time was added to the latency score of the next section forward. If the rat did not enter the goalbox within $90 \mathrm{sec}$, it was placed in the goalbox.

\section{Results}

Times from each alley section and over the total alley for each rat were converted into speeds in centimeters/second in both of the experiments reported here. Only total speeds, which are representative of responding in each alley section, are reported. As expected, differences in resistance to discrimination as a function of S+ PRF sequence were manifested primarily in $\mathrm{S}-$ behavior. The left panel of Figure 1 shows the mean speed of each of the four groups in $\mathrm{S}-$ in blocks of 2 days. The right panel shows the mean speed of each group on the last day in $\mathrm{S}+$ and on each of the five daily extinction trials collapsed across the 3 days of extinction.

As can be seen in Figure 1, Group RRRN ran more slowly than the remaining three groups in $\mathrm{S}-$ during discrimination training and showed as rapid a rate of extinction as Group CRF. Groups RRNR and NRRR performed essentially alike, both in $\mathrm{S}-$ and in extinction, with both groups responding at a level intermediate to that of Groups RRRN and CRF during discrimination training and running faster during extinction than Groups RRRN and CRF.

An analysis of variance (ANOVA) was applied to mean daily speeds over the last 4 days in each discriminandum (last 8 days of training). Daily means, rather than scores on individual trials, were used as the data for the ANOVA because of the different number of trials on $\mathrm{S}+$ and $\mathrm{S}-$ days. The ANOVA included groups (4) and the counterbalancing of brightness (2) as between-subjects factors. Discrimi-
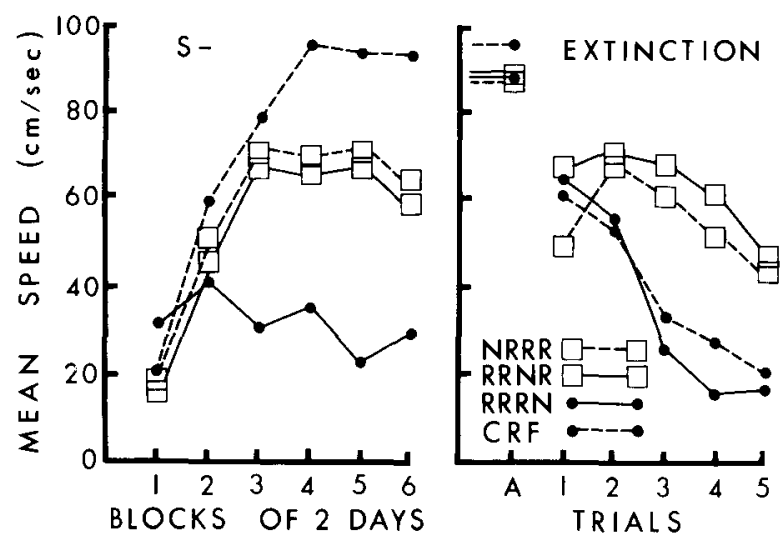

Figure 1. Mean speed in $S-$ in blocks of 2 days (left panel) and over the five daily extinction trials collapsed across the 3 days of extinction (right panel) over the total alley for each of the four groups in Experiment 1. The right panel also shows speeds on the last day of training in $S+(A)$. nanda (2) and days (4) were the within-subjects factors. The important finding in the ANOVA was a reliable Groups by Discriminanda interaction $[F(3,32)$ $=8.28, \mathrm{p}<.001]$.

Partitioning the Groups by Discriminanda interaction into simple effects of discriminanda at each group showed that $\mathrm{S}+$ speeds were faster than $\mathrm{S}-$ speeds in each of the PRF groups [smallest $F(1,32)=$ $12.79, \mathrm{p}<.01$, for Group NRRR]. Group CRF did not respond differentially in $S+$ and $S-(F<1)$. The Groups by Discriminanda interaction was also partitioned into simple effects of groups at $\mathrm{S}+$ and at $\mathrm{S}-$. These tests required a pooled error term. The appropriate adjustment in degrees of freedom was made using the Saterthwaite approximations recommended by Winer (1971). Differences among groups were reliable in $\mathrm{S}-[\mathrm{F}(3,58)=20.06, \mathrm{p}<.001]$ but not in $S+[F(3,58)=1.70]$. Newman-Keuls tests applied to speeds in $\mathrm{S}$ - showed that Group RRRN ran significantly more slowly than each of the remaining three groups (all ps $<.05$ ) and that Groups NRRR and RRNR ran reliably more slowly than Group CRF (ps <.01). There was no difference in speed of running in $\mathrm{S}-$ between Groups NRRR and RRNR.

A 4 (groups) by 2 (brightness) by 3 (days) by 5 (trials) between-within ANOVA applied to speeds over the 15 extinction trials yielded reliable effects of groups $[F(3,32)=4.40, p<.01]$ and Groups by Trials $[F(12,128)=6.93, p<.001]$. Newman-Keuls tests applied to group mean speeds over the 15 extinction trials showed that Groups NRRR and RRNR were more resistant to extinction than Groups RRRN and CRF (ps $<.01$ ) and that there were no other differences among groups in resistance to extinction.

\section{Discussion}

In Experiment 1, Groups NRRR and RRNR received a PRF schedule that contained N-R transitions in the $\mathrm{S}+$ alley during differential conditioning. Both groups showed greater resistance to discrimination (faster speeds in the S- alley) than Group RRRN given the same percentage of PRF in $S+$ on a schedule that did not provide within-day $\mathrm{N}-\mathrm{R}$ transitions. The sequence of S+ PRF had no effect on $\mathrm{S}+$ behavior.

The effects of $\mathrm{S}+$ reward sequence on resistance to extinction in $\mathrm{S}+$ closely paralleled the effects on $\mathrm{S}-$ behavior. The groups were ordered in resistance to extinction RRNR $=$ NRRR $>$ RRRN $=$ CRF.

The effects of $N-R$ transitions in Experiment 1 were predicted from an extension of Capaldi's (1966, 1967) sequential theory to differential conditioning. According to the sequential view, speed of running during extinction following PRF is an increasing function of N-R transitions (Capaldi, 1966; Capaldi, Hart, \& Stanley, 1963). In the present experiment, 
running speed in $\mathrm{S}-$ during differential conditioning and in subsequent extinction in $\mathrm{S}+$ was increased by $\mathrm{N}-\mathrm{R}$ transitions. This finding is consistent with the increased resistance to discrimination produced by $\mathrm{S}-\mathrm{S}+$ transitions obtained in previous experiments (Capaldi et al., 1975; Haggbloom, 1978).

According to the present view, N-R and S-S+ transitions both function to condition responding to $\mathrm{S}^{\mathrm{N}}$, and resistance to discrimination, like resistance to extinction, is due to the associative control over behavior exercised by $\mathrm{S}^{\mathrm{N}}$. Still, it is possible that all three PRF schedules, including RRRN, produced some increase in resistance to discrimination. However, this seems unlikely for Group RRRN, since that group did not show a partial reinforcement extinction effect (PREE) in S+. The absence of a PREE in Group RRRN confirms that $S^{N}$ exercised little or no control over behavior in that group. Note, in this context, that it is important in discrimination learning (Haggbloom, 1979), as in PRF (Capaldi \& Morris, 1974), that the value of $S^{N}$ varies as a function of intertrial interval (ITI) and that a marked reduction in behavioral control occurs if the value of $\mathrm{S}^{\mathrm{N}}$ conditioned to the response differs from that present in $\mathrm{S}-$ or extinction, in this case a 4-min ITI value. Groups RRNR and RRRN here received N-R transitions from $S-$ to $S+$ over a 24 -h ITI, but those transitions would have conditioned a $24-\mathrm{h}$ ITI value of $S^{\mathrm{N}}$.

Previous experiments have reported a PREE following differential conditioning (Brown \& Logan, 1965; MacKinnon, 1967) and have shown that the locus of N-R transitions, for example, within $\mathrm{S}+$ as in the present experiment or from $\mathrm{S}-$ to $\mathrm{S}+$, determines whether resistance to extinction is increased in S-, S +, or both (e.g., Mellgren \& Dyck, 1972). The present extinction results are unique in demonstrating that the PREE following differential conditioning, as in conventional PRF, occurs only in groups given $\mathbf{N}-\mathbf{R}$ transitions.

\section{EXPERIMENT 2}

The results of Experiment 1 agree with those of previous experiments (Capaldi, 1979; Capaldi et al., 1975; Haggbloom, 1978, 1979; McHose \& Blackwell, 1975 ) in demonstrating a high degree of similarity between sequential effects on resistance to extinction following PRF and extinction of responding to Sduring differential conditioning. In conventional PRF, however, responding is somewhat less strongly conditioned to $\mathrm{S}^{\mathrm{N}}$ if $\mathrm{S}^{\mathrm{N}}$ is occasioned in a context, for example, goalbox color, that differs from that present on R trials (Capaldi \& Spivey, 1963). S-S+ transitions in differential conditioning represent an analogous contextual change situation. As already indicated, there is some dispute over whether $\mathrm{S}^{\mathrm{N}}$ occasioned in $\mathrm{S}-$ is retrieved on a subsequent trial in
$\mathrm{S}+$. While $\mathrm{S}-\mathrm{S}+$ transitions increase resistance to discrimination (Haggbloom, 1978), they may do so less effectively than $\mathrm{N}-\mathrm{R}$ transitions within $\mathrm{S}+$. On the other hand, $\mathrm{N}-\mathrm{R}$ transitions with $\mathrm{S}+$ condition responding to $S^{N}$ within $S+$ and yet retard extinction of responding in a different context, viz, $\mathrm{S}-$. The purpose of Experiment 2 was to provide a direct comparison of the effects of S-S + transitions and $\mathrm{N}-\mathrm{R}$ transitions in $\mathrm{S}+$ on both resistance to discrimination and subsequent resistance to extinction in S+.

As in Experiment $1, \mathrm{~S}+$ and $\mathrm{S}-$ trials were presented on alternate days. In a 2 by 2 factorial arrangement, groups received a reward schedule on odd-numbered $\mathrm{S}+$ days that contained (RRNR) or did not contain (RRRN) an N-R transition. Groups RRNR-S and RRRN-S received the N-trial component of the PRF schedule in the same alley as their $\mathrm{S}+$ trials. Groups RRNR-D and RRRN-D received the N-trial component of the PRF schedule in a different alley, that is, $\mathrm{S}-$. Thus, Group RRNR-S received $N-R$ transitions within $S+$, whereas Group RRNR-D received $S-S+$ transitions. Group RRRN-S controls for the occurrence of nonreward in $\mathrm{S}+$; Group RRRN-D controls for the occurrence of an additional S- trial.

\section{Method}

Subjects. The subjects were 40 male rats bred in the laboratory from Holtzman stock. The rats were $90-110$ days old at the start of the experiment.

Apparatus. The apparatus was the same as in Experiment 1.

Procedure. All procedures prior to the first day of discrimination training were identical to those in the preceding experiment.

All rats received three rewarded trials and one nonrewarded trial on each of the first 3 days of training and on each odd-numbered day thereafter. The reinforcement schedule on those days was RRNR for rats in Groups RRNR-S and RRNR-D and RRRN for Groups RRRN-S and RRRN-D. The nonrewarded trial on those days occurred in the same alley as the rewarded trials (S+ alley) in Groups RRNR-S and RRRN-S. In Groups RRNR-D and RRRN-D, the nonrewarded trial occurred in the S- alley. This arrangement constituted a 2 by 2 factorial combination of $\mathrm{S}+$ PRF sequence and location of the $\mathrm{N}$-trial component of that sequence. Groups RRNR-S and RRNR-D received N-R transitions on $\mathrm{S}+$ days either within $\mathrm{S}+$ (Group RRNR-S) or from $\mathrm{S}-$ to $\mathrm{S}+$ (Group RRNR-D). Beginning on Day 4 and on each even-numbered day thereafter, each group received four nonrewarded trials in the $\mathrm{S}-$ alley. Following the first 2 days of training on the S+ schedule, then, there were six complete cycles of $S+$ and $S$ - days in Experiment 2.

Following discrimination training, there were 3 days of extinction. During extinction, each group received five trials per day in the $\mathrm{S}+$ alley.

\section{Results}

Only total speeds, which are representative of responding in each alley section, are reported. The left panel of Figure 2 shows the mean speed of each of the four groups in blocks of two S- days. Trial 1 on $\mathrm{S}$ - days was omitted from the figure and, along with the $\mathrm{N}$ trial on $\mathrm{S}+$ days, from all analyses. The right 


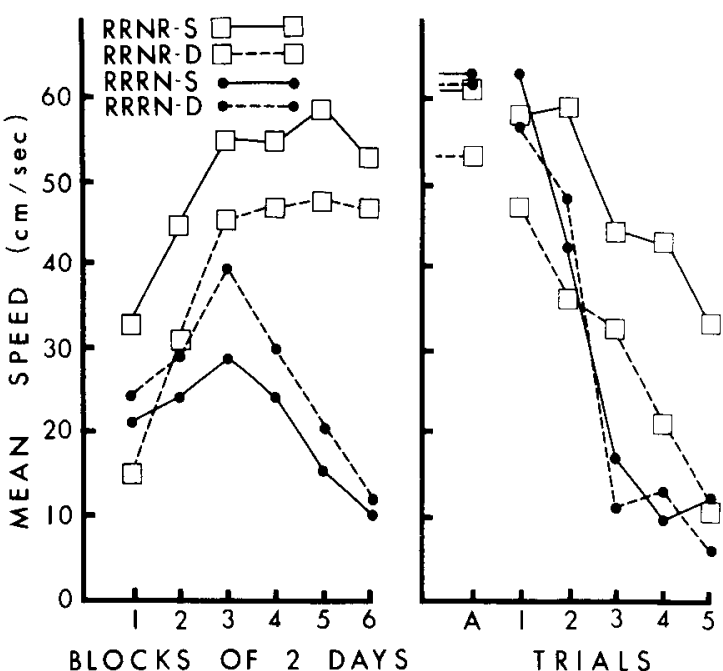

Figure 2. Mean speed in S- in blocks of 2 days (left panel) and over the five daily extinction trials collapsed across the first 2 days of extinction (right panel) over the total alley for each of the four groups in Experiment 2. The right panel also shows speeds on the last day of training in $S+$ (A).

panel of Figure 2 shows speeds on each of the five daily extinction trials collapsed across the first 2 days of extinction. There were no differences among groups on Day 3 of extinction, so those data were omitted from the figure and all analyses.

As can be seen in Figure 2, both resistance to discrimination and resistance to extinction were greater in the RRNR schedule condition than in the RRRN condition. There was a slight difference in $\mathrm{S}-$ behavior favoring faster speeds in Group RRNR-S than in Group RRNR-D. There was little difference between the performance of Groups RRRN-S and RRRN-D in S-. In extinction, Group RRNR-S ran considerably faster than Group RRRN-S, whereas the difference between Groups RRNR-D and RRRN-D was relatively small. The relatively rapid rate of extinction in Group RRNR-D may reflect the lower level of responding in that group in $\mathrm{S}+$ at the end of discrimination training. There was no difference in extinction performance between Groups RRRN-S and RRRN-D.

An ANOVA was applied to speeds in $\mathrm{S}+$ and $\mathrm{S}-$ on the last 2 days (last cycle) of discrimination training that included two levels of S+ PRF schedule (RRNR vs. RRRN), two levels of N-trial locus (S+ or $\mathrm{S}-$ ), and the counterbalancing of brightness as between-subjects factors. The within-subjects factors were trials (3) and discriminanda (2).

The ANOVA revealed a highly reliable Schedule by Discriminanda interaction $[F(1,32)=77.34, p<$ $.001]$ but no interaction of $\mathrm{N}$-trial locus with discriminanda $(F<1)$ or three-way interaction of Schedule by $\mathrm{N}-\mathrm{Trial}$ Locus by Discriminanda $(\mathrm{F}<1)$. Planned comparisons between $\mathrm{S}+$ and $\mathrm{S}-$ speeds in each group (all $\mathrm{df}=1,32$ ) showed that all four groups were running faster in $\mathrm{S}+$ than in $\mathrm{S}-$ by the end of training (smallest $F=18.30, p<.01$, for Group RRNR-S). Simple effects of schedule at $S-$ showed that the RRRN schedule resulted in slower $S-$ speeds than the RRNR schedule $[F(1,57)=57.68, p<.001]$. There were no reliable differences due to $\mathrm{N}$-trial locus in $S-[F(1,57)=2.49]$ and no simple interaction between schedule and $\mathrm{N}$-trial locus $[\mathrm{F}(1,57)=3.86]$. Within $\mathrm{S}+$, there were no differences among groups due to schedule, $\mathrm{N}$-trial locus, or their interaction [largest $\mathrm{F}(1,57)=1.49$ ].

A 2 (schedule) by 2 ( $\mathrm{N}$-trial locus) by 2 (brightness) by 5 (trials) by 2 (days) between-within ANOVA applied to speeds over the first 2 days of extinction yielded a reliable Schedule by $\mathrm{N}$-Trial Locus interaction $[F(1,32)=4.38, p<.05]$. Simple effects of schedule showed that Group RRNR-S was more resistant to extinction than Group RRRN-S $[F(1,32)=$ $11.25, \mathrm{p}<.011$. Group RRNR-D was not more resistant to extinction than Group RRRN-D (F $<1)$. Differences due to $\mathrm{N}$-trial locus were reliable in the RRNR schedule condition $[F(1,32)=10.06, p<.01]$ but not in the RRRN condition $(F<1)$. Thus, only Group RRNR-S showed a PREE, and the location of the N trial on S + days influenced extinction behavior only in the RRNR schedule condition.

\section{Discussion}

The results of Experiment 2 agree with those of Experiment 1 in demonstrating that N-R transitions within $\mathrm{S}+$ provided by the RRNR schedule produce greater resistance to discrimination and greater resistance to extinction than occurs in groups given the $\mathrm{S}+$ PRF sequence RRRN, which does not contain $\mathrm{N}-\mathrm{R}$ transitions. Moreover, Group RRNR-D, which received $\mathrm{S}-\mathrm{S}+$ transitions during differential conditioning, was more resistant to discrimination than Group RRRN-D and nearly as resistant to discrimination as Group RRNR-S. That finding suggests that, at least with a small number of trials, N-R transitions within a single stimulus and $\mathrm{S}-\mathrm{S}+$ transitions are approximately equally effective in retarding discrimination learning.

\section{GENERAL DISCUSSION}

In conventional PRF, the availability of reinforcement on a trial is not signaled by differential external cues, and responding in both acquisition and extinction is extensively regulated by the sequence of rewards and nonrewards experienced during acquisition (Capaldi, 1966, 1967). Discrimination problems in which one stimulus, $\mathrm{S}_{+}$, is associated with reinforcement and another, $\mathrm{S}-$, is paired with nonreinforcement are similar to conventional PRF except for the fact that the availability of reinforcement is signaled during discrimination learning. Because the rat must learn to respond to a stimulus as a signal for reinforcement or nonreinforcement, whether such learning involves attentional, motivational, or 
associative processes, there should be a high degree of similarity between conventional PRF and at least the early trials of discrimination learning.

The results of the present experiments support the view that discrimination learning and PRF, especially behavior in $\mathrm{S}-$ and in extinction following PRF, are highly interrelated phenomena. In the present experiments, speed of running in S-, or resistance to discrimination, was increased in groups given transitions from $\mathrm{N}$ to $\mathrm{R}$ trials either within $\mathrm{S}+$ or from $\mathrm{S}-$ to $S+$ compared with groups given no transitions of either type from $N$ to $R$ trials. The effects of $N-R$ transitions on resistance to discrimination were predicted from an extension of Capaldi's $(1966,1967)$ sequential theory to differential conditioning (e.g., Capaldi et al., 1975; Haggbloom, 1978) and closely parallel the effects of N-R transitions on resistance to extinction following PRF. The effects of N-R and $\mathrm{S}-\mathrm{S}+$ transitions reported both here and previously (Haggbloom, 1978) would appear to be major factors underlying latent discrimination learning (see Capaldi, 1979), that is, the masking of appropriate behavior to $\mathrm{S}+$ and $\mathrm{S}-$ in conventional differential conditioning.

The present findings and those of $\mathrm{McHose}$ and Blackwell (1975) that the sequence of reward events in $\mathrm{S}+$ is an important determinant of $\mathrm{S}-$ behavior also has important implications for the notion (McHose, 1970) that the average incentive disparity between $\mathrm{S}+$ and $\mathrm{S}-$ is a major determinant of $\mathrm{S}-$ behavior. Average reward in $\mathrm{S}+$ has been manipulated between groups by employing partial or varied reward in $\mathrm{S}+$ vs. consistent reward in $\mathrm{S}+$ (e.g., McHose, McHewitt, \& Peters, 1972; McHose \& Peters, 1973). While those experiments lent considerable support to the incentive averaging notion, differences among groups in sequential variables were not controlled. The importance of controlling sequential variables in tests of the incentive averaging hypothesis is indicated by the differences in discriminative behavior obtained here in Experiments 1 and 2 between groups given the RRNR schedule and those given the RRRN schedule in S+. Both schedules provide the same average reward in $\mathrm{S}+$, yet discrimination learning was markedly better under the RRRN schedule. The effects of average reward in $\mathrm{S}+$ need to be separated from those of sequential variables.

\section{REFERENCES}

Brown, R. T., \& Logan, F. A. Generalized partial reinforcement effect. Journal of Comparative and Physiological Psychology, $1965,60,64-69$.
Campbell, E. D., \& Meyer, P. A. Effects of daily. reward sequence on simultaneous and successive negative contrast in rats. Journal of Comparative and Physiological Psychology, 1971, 74, 434-440.

CAPALdi, E. J. Partial reinforcement: An hypothesis of sequential effects. Psychological Review, 1966, 73, 459-477.

CAPAldi, E. J. A sequential hypothesis of instrumental learning. In K. W. Spence \& J. T. Spence (Eds.), The psychology of learning and motivation (Vol. 1). New York: Academic Press, 1967.

CAPAldi, E. J. Latent discrimination learning under a regular schedule of partial reinforcement. Animal Learning \& Behavior, $1979,7,63-68$.

Capaldi, E. J., Berg, R. F., \& Morris, M. D. Stimulus control of responding in the early trials of differential conditioning. Learning and Motivation, 1975, 6, 217-229.

Capaldi, E. J., Hart, D., \& Stanley, L. R. Influence of intertrial reinforcement on the aftereffect of nonreinforcement and resistance to extinction. Journal of Experimental Psychology, $1963,65,70-74$.

Capaldi, E. J., \& Morris, M. D. Reward schedule effects in extinction: Intertrial interval, memory, and memory retrieval. Learning and Motivation, 1974, 5, 473-483.

Capaldi, E. J., \& Spivey, J. E. Effect of goal-box similarity on the aftereffect of nonreinforcement and resistance to extinction. Journal of Experimental Psychology, 1963, 66, 461-465.

HAGGBLOOM, S. J. Intertrial interval effects on internal stimulus control of behavior in brightness differential conditioning. Learning and Motivation, 1978, 9, 347-348.

HaGgBloom, S. J. The differential reinforcement of rewardproduced and response-produced stimuli. Learning and Motivation, 1979, 10, 364-381.

MacKinnon, J. R. Interactive effects of the two rewards in a differential magnitude of reward discrimination. Journal of Experimental Psychology, 1967, 75, 329-338.

McHose, J. H. Relative reinforcement effects: $S_{1} / S_{2}$ and $S_{1} / S_{1}$ paradigms in instrumental conditioning. Psychological Review, $1970,77,135-146$.

McHose, J. H., \& Blackwell, D. R. Performance in differential instrumental conditioning as a function of the pattern of partial S+ reward. Animal Learning \& Behavior, 1975, 3, 63-66.

McHose, J. H., McHewitt, E. R., \& Peters, D. P. Average reward as a determinant of S- performance in differential conditioning. Psychonomic Science, 1972, 29, 129-132.

McHose, J. H., \& PETERS, D. P. Differential instrumental conditioning as a function of the percentage and amount of $\mathrm{S}+$ reward. Journal of Experimental Psychology, 1973, 100, 413-415.

Mellgren, R. L., \& Dyck, D. G. Partial reinforcement effect, reverse partial reinforcement effect, and generalized partial reinforcement effect within-subjects. Journal of Experimental Psychology, 1972, 92, 339-346.

Meyer, P. A., \& Campbell, E. M. Role of daily reward sequence on S- discrimination contrast in rats. Journal of Comparative and Physiological Psychology, 1973, 82, 426-433.

WINER, B. J. Statistical principles in experimental design (2nd ed.). New York: McGraw-Hill, 1971.
(Received for publication October 18, 1979; revision accepted January 28,1980 .) 